\title{
LA TRANSFORMACIÓN DE LAS FUNCIONES DEL ESTADO MEXICANO EN TORNO A LA DIALÉCTICA DESARROLLO/SUBDESARROLLO: INCURSIONES A LA LUZ DE LA CRISIS INSTITUCIONAL CONTEMPORÁNEA*
}

\author{
The transformation of the functions of the Mexican State \\ around the dialectic development / underdevelopment: \\ incursions in light of the contemporary institutional crisis
}

\author{
Isaac Enríquez Pérez \\ Universidad Nacional Autónoma de México \\ isaacep@unam.mx
}

http://dx.doi.org/10.18543/ed-67(1)-2019pp185-221

Recibido: 14.11.2018

Aceptado: 21.06.2019

\section{Resumen}

A través del presente artículo se pretende estudiar el hecho de que las funciones del Estado tienden a cambiar históricamente en México y que no se muestran de

* Cómo citar / Citation 'Chicago-Deusto' (Autor-fecha / Author-date / Lista de referencias / Reference list entries): Enríquez Pérez, Isaac. 2019. «La transformación de las funciones del Estado mexicano en torno a la dialéctica desarrollo/subdesarrollo: incursiones a la luz de la crisis institucional contemporánea». Estudios de Deusto 67, n. ${ }^{\circ}$ 1: 185-221. http://dx.doi.org/10.18543/ed-67(1)-2019pp185-221.

Este trabajo fue realizado como parte de las actividades de post-doctorado en la Unidad Académica en Estudios del Desarrollo de la Universidad Autónoma de Zacatecas y financiado por el Consejo Nacional de Ciencia y Tecnología (CONACyT) a través de su Programa de Estancias de Investigación Vinculadas al Fortalecimiento de la Calidad del Posgrado Nacional. 
manera homogénea en los esfuerzos de esta macroestructura institucional por incidir en la dialéctica desarrollo/subdesarrollo. Dichos cambios, están en función de la reconfiguración del capitalismo como modo de producción y proceso civilizatorio, así como de la gravitación que ejercen -en medio de la transnacionalización de las decisiones públicas estratégicas y de la transcontinentalización de las relaciones sociales- los espacios globales para la toma de decisiones. A partir del objetivo que consiste en identificar e interpretar el sentido de esas renovadas funciones estatales, se trata de incursionar en la orientación que toman las decisiones púbicas y las distintas fuerzas, factores y circunstancias que inciden en la planeación del desarrollo en una nación subdesarrollada como México; no sin dejar de lado las especificidades de las políticas públicas y de las estrategias de intervención del sector público en un escenario signado por una crisis de Estado cada vez más pronunciada a causa de la proliferación de poderes fácticos que le disputan la articulación de la vida social.

\title{
Palabras clave
}

Dialéctica desarrollo/subdesarrollo; funciones del Estado; decisiones públicas; planeación del desarrollo; espacios globales para la toma de decisiones; crisis de Estado.

\begin{abstract}
Through this article we intend to study the fact that the functions of the State tend to change historically in Mexico and that they do not show homogeneously in the efforts of this institutional macrostructure to influence the dialectic of development/ underdevelopment. These changes, are a function of the reconfiguration of capitalism as a mode of production and civilizatory process, as well as of the gravitation exercised - in the middle of the transnationalization of strategic public decisions and the transcontinentalization of social relations - the global spaces for decision making. Starting from the objective that consists of identifying and interpreting the meaning of these renewed state functions, it is about entering into the direction taken by the public decisions and the different forces, factors and circumstances that affect the planning of development in an underdeveloped nation such as Mexico; not without leaving aside the specificities of public policies and intervention strategies of the public sector in a scenario marked by a state crisis increasingly pronounced because of the proliferation of factual powers that dispute the articulation of social life.
\end{abstract}

\section{Keywords}

Dialectic development/underdevelopment; State functions; public decisions; development planning; global spaces for decision making; State crisis. 


\begin{abstract}
SUMARIO: I. INTRODUCCION. II. LAS FUNCIONES ESENCIALES DEL ESTADO EN LA CONSTRUCCIÓN DE MERCADOS Y EN LA (RE)DISTRIBUCIÓN DE LA RIQUEZA: NOTAS PARA UN PANORAMA GENERAL. III. DEL ESTADO DESARROLLISTA AL ESTADO MÍNIMO Y SITIADO POR LOS (CONTRA)PODERES FÁCTICOS: LA ENTRONIZACIÓN DEL FUNDAMENTALISMO DE MERCADO EN MÉXICO. IV. EL ESTADO MEXICANO Y LOS INTERSTICIOS DE LA PLANEACIÓN DEL DESARROLLO: ENTRE LOS ESPACIOS GLOBALES PARA LA TOMA DE DECISIONES Y LOS PROBLEMAS PÚBLICOS LOCALES/NACIONALES. V. LA RECONFIGURACIÓN DE LAS FUNCIONES DEL ESTADO MEXICANO DE CARA A LA CRISIS INSTITUCIONAL Y EL AHONDAMIENTO DE LAS CONTRADICCIONES DEL CAPITALISMO PERIFÉRICO. VI. LAS COORDENADAS DEL ESTADO MEXICANO EN LA CARTOGRAFÍA ESTRATIFICADA DE LA ECONOMÍA MUNDIAL. VII. CONSIDERACIONES FINALES SOBRE LA INVESTIGACIÓN. VIII. FUENTES DE CONSULTA UTILIZADAS EN LA INVESTIGACIÓN.
\end{abstract}

\title{
I. INTRODUCCIÓN
}

La forma histórica que adopta la construcción de mercados y la (re)distribución de la riqueza en el capitalismo es definida, en buena medida, por la especificidad de las funciones del Estado; así como por los rasgos característicos propios de las políticas públicas, en tanto instrumentos de intervención para la modelación, modulación, organización y dirección de una sociedad. A su vez, esas funciones del Estado, sus entramados institucionales y el mismo proceso de toma de decisiones públicas muestran una relación dialéctica y bidireccional con las transformaciones estructurales y organizacionales del capitalismo. Esto es, la estructuración del Estado, sus instituciones y acciones concretas son condicionadas por la naturaleza y las especificidades históricas de los mercados, de los patrones de acumulación y de la modalidad de organización adoptada por la empresa en sus esfuerzos para la valorización del capital, el aumento de la tasa de ganancia, el estímulo de la innovación y para el incremento de la productividad. Más allá del determinismo economicista, entre el proceso económico, el Estado y la praxis política que éste entraña, lo que se presenta es una intergénesis que le da forma a los cauces de la dialéctica desarrollo/subdesarrollo y a los mecanismos de intervención y regulación que una sociedad organizada define para hacer frente a la reestructuración, contradicciones, asimetrías y cambios del capitalismo.

Particularmente y desde 1985, en México la transformación del sentido de las políticas públicas $-\mathrm{y}$ de las respectivas concepciones y estrategias del modelo de desarrollo arraigado en ellas- respondió a los imperativos de la crisis de la deuda y a la reconfiguración misma experimentada por el modo de producción capitalista. Estos cambios en el capitalismo se 
fundamentan en la emergencia de una nueva división global del trabajo y en la expansión de los sistemas internacionales de producción integrada, entrelazados -a su vez- con encadenamientos mercantiles mundiales y con redes financieras globales; a los cuales -en su conjunto- ésta economía nacional se inserta de manera desventajosa y asimétrica. De ahí que las funciones, las instituciones y la (re)estructuración del Estado mexicano se correlacionan en múltiples direcciones con las transformaciones en el patrón de acumulación y en el comportamiento de los mercados. Reconocido esto, cabe postular algunas preguntas que le dieron sentido a la investigación que sustenta estas páginas: ¿Cuáles son y en qué consisten los principales cambios experimentados por el Estado en México desde 1985? ¿Cuáles son las funciones e intervenciones que, desde, entonces despliega en torno a la contradictoria dialéctica desarrollo/subdesarrollo? ¿De qué manera incide esta nueva orientación del Estado mexicano en el proceso de acumulación de capital y en la (re)distribución de la riqueza? ¿Cómo inciden estas transformaciones del Estado mexicano en el proceso de planeación y cuáles son los márgenes de maniobra ante la gravitación de espacios globales para la toma de decisiones y el agravamiento de los problemas públicos locales/nacionales? ¿Cuáles son las especificidades que adoptan las funciones del Estado en las distintas latitudes del mundo y, particularmente, en México respecto a rubros como la construcción de mercados y la procuración de un mínimo bienestar social? Planteadas estas preguntas de investigación, cabe matizar que el objetivo general del presente artículo consiste en desentrañar, comprender e interpretar el sentido del Estado mexicano y sus funciones esenciales a la luz de las transformaciones endógenas y exógenas que inciden en el curso de la dialéctica desarrollo/subdesarrollo y en los procesos de planeación, así como de las fuerzas, factores y agentes que les dan forma en el México contemporáneo. Esto es, se trata de analizar la reconfiguración del perfil del Estado y el sentido que adquieren en este contexto las decisiones públicas respecto a ámbitos como el proceso económico, la creación de instituciones y la modelación de la sociedad. Ello sin perder de vista el ejercicio de comparabilidad internacional.

Una premisa relevante que inspiró la reflexión y la investigación que subyacen en el presente texto fue la siguiente: la estrecha correspondencia que existe en México entre la reorientación de las concepciones sobre el desarrollo contenidas en las políticas públicas, el cambio de modelo económico y la reestructuración del Estado, tiene como correlato la emergencia y consolidación de (contra)poderes fácticos que le disputan la hegemonía a éste último; así como la generalización de una crisis institucional que incide en las decisiones públicas y que tiene como trasfondo la entronización del mercado (del individuo) y la subsunción y declive de lo público. 


\section{LAS FUNCIONES ESENCIALES DEL ESTADO EN LA CONSTRUCCIÓN DE MERCADOS Y EN LA (RE)DISTRIBUCIÓN DE LA RIQUEZA: NOTAS PARA UN PANORAMA GENERAL}

El Estado es una macroestructura institucional que sintetiza y condensa los variados y hasta contrapuestos intereses ostentados por los distintos grupos sociales que se disputan el control sobre la modelación, configuración y organización de la sociedad. Particularmente, la génesis, reproducción, irradiación y profundización del capitalismo - en tanto modo de producción y proceso civilizatorio- serían inconcebibles sin el Estado y las funciones que históricamente adopta respecto a la construcción de mercados y la (re)distribución de la riqueza.

Más aún, el Estado es un denso entramado institucional dotado de relaciones de subordinación y orientado a mediar, encauzar y atemperar los conflictos sociales y la multiplicidad de ideologías, concepciones e intereses que, desde arriba y desde abajo, inciden en la construcción de las instituciones que regulan la sociedad y tornan funcionales la estratificación y la desigualdad social. Sin esta arena que encauza el conflicto y regula el carácter desbocado de variadas relaciones sociales donde impera el individualismo por encima de lo colectivo, las posibilidades de integración y cohesión social serian mínimas; en tanto que las naciones se disolverían en la confrontación y la anarquía. El Estado es una síntesis de los principios, valores, imaginarios sociales, cosmovisiones, idiosincrasias, historias, culturas, simbolismos, identidades, recursos, necesidades, deseos y aspiraciones, proyectos de nación; así como de las leyes y normas que rigen la conducta y el comportamiento de los individuos y las comunidades.

Las funciones, objetivos e intervenciones del Estado son una síntesis de los intereses y necesidades mostrados -bajo distintos niveles de organización y cohesión- por las élites dominantes y los grupos sociales dominados. Como los posicionamientos y el comportamiento de ambos responden a relaciones de poder y a la correlación de fuerzas -la mayoría de las veces asimétricas-, el sentido de su acción social está dado por su aspiración de influir de manera ventajosa en los problemas públicos, las instituciones, las estructuras ideológicas y jurídicas; así como en los mecanismos propios de la asignación de recursos y de la distribución de la riqueza. Sin embargo, ni la correlación de fuerzas interna, ni el perfil que adopta el Estado y su posicionamiento en la economía mundial y la política internacional, dependen exclusivamente de factores endógenos; sino que también están expuestos a agentes, organizaciones, espacios de toma de decisiones, factores, circunstancias y condicionamientos exógenos que le dan forma a los entramados institucionales nacionales.

Entre esas funciones esenciales que, históricamente, despliega -o intenta ejercer- el Estado sobresalen la configuración y estructuración del espacio 
público; la creación de normas y leyes a observar por los individuos en sus relaciones sociales y en el ejercicio de su conducta; la preservación de la integridad física de los ciudadanos y la procuración de la seguridad pública; la resolución de conflictos y la impartición de justicia; el control social para abonar a la estabilidad sociopolítica; la construcción y regulación del proceso económico; la vocación para mediar e incidir directamente en la construcción de las leyes sociales y en las relaciones de poder que definen la distribución de la riqueza; el establecimiento y garantía de los derechos de propiedad; el diseño y ejercicio de políticas sociales y la provisión de mínimos servicios para la seguridad social; la estipulación y garantía de los derechos individuales y sociales; la producción, mantenimiento y provisión de bienes públicos y bienes comunes; el ejercicio de la política exterior y de las estrategias de defensa y seguridad nacional; entre otras.

Más allá de la falsa disyuntiva que impregna a la historia del pensamiento económico (¿más mercado, o más Estado?), respecto al proceso económico, el sector público despliega varias funciones cruciales que es necesario comprender. Por un lado, para la fase de producción, el Estado sienta los entramados institucionales para el despliegue de la relación capital/trabajo y legitima -a través de la estructura jurídica- la creación y apropiación de la plusvalía. Además, crea las instituciones para las relaciones laborales, el régimen salarial y para la fijación del valor de la fuerza de trabajo; al tiempo que con sus normas, leyes y convencionalismos disciplina el cuerpo y la mente de la clase trabajadora contratada por la empresa. No menos importante es el papel del Estado en la provisión de infraestructura básica y de servicios de formación y capacitación técnica de la fuerza de trabajo para su inserción en las organizaciones productivas; así como la configuración, delimitación, ordenamiento, segmentación y gestión del territorio $-\mathrm{y}$, especialmente, del espacio urbano-donde se asienta el proceso de producción. Más todavía, el sector público estimula y financia procesos de cambio tecnológico e innovación, y la organización de procesos que detonan economías de escala; al tiempo que asume la provisión de ciertos bienes y servicios que no son de interés del empresariado privado (alumbrado público, carreteras, vías de comunicación, resguardo de los medios de producción, seguridad nacional, etcétera), pero que son fundamentales para la producción a partir de la socialización de ciertos costos de la misma que, en última instancia, son sufragados con los impuestos y el gasto público. Sin todas estas funciones básicas del Estado, el proceso de valorización y acumulación de capital sería inviable y estaría regido por la anarquía.

Con relación a la fase de circulación e intercambio, el Estado incide en el sistema de precios y en su funcionamiento a través de una estructura jurídica para el despliegue del mecanismo de mercado (la garantía de los derechos de propiedad y el cumplimiento de los contratos a través de esas leyes es 
fundamental para ello) y la preservación de condiciones mínimas de competencia. Este sistema de precios es modificado y complementado a través de funciones estatales como la procuración del bienestar social; y el ajuste de la composición del producto total, tomando en cuenta costes e ingresos sociales, y suponiendo ello atenuar las externalidades propias del proceso económico y regular las conductas y acciones que los agentes privados despliegan ante ellas. No menos importante para el sistema de precios es el control de la inflación y el desempleo, que son consustanciales a la dinámica del proceso económico; así como la provisión de servicios y bienes públicos no rentables como la seguridad pública, el ejército, la policía, las prisiones, el alumbrado público, las vías de comunicación, los parques y demás áreas verdes (sobre estas funciones relacionadas con el sistema de precios consúltese McConnell, 1972: capítulo 6). En suma, el Estado crea el entorno institucional y brinda la infraestructura necesaria para la perpetuación de la relación mercantil/monetaria.

Una serie de funciones e intervenciones cruciales las realiza el Estado en la fase de distribución; siendo ello la mayor diferencia en el grado de bienestar entre una estructura social (o una nación) y otra. Entre estas intervenciones destacan: garantizar un salario directo (lo pagado a través de la nómina cada quincena o cada mes, de acuerdo al aumento de la productividad y los precios); un salario indirecto (prestaciones sociales, seguridad social, acceso a servicios de educación y salud); y un salario diferido (régimen de pensiones y jubilaciones) para la clase trabajadora y su reproducción social. Mediante la recaudación de impuestos (política fiscal) y la provisión y cobro de bienes y servicios, el Estado incide en la redistribución de la riqueza; al tiempo que a través de la política social y la seguridad social puede hacer del crecimiento económico un mecanismo que incide en la calidad de vida de la población, y estimula la fase de consumo al realizar transferencias monetarias a grupos sociales excluidos por el mercado (por ejemplo, el seguro de desempleo concedido por los Estados de bienestar europeos, y los apoyos focalizados del nuevo asistencialismo en países como México).

En la fase de consumo, el Estado garantiza un salario mínimo para procurar la producción y reproducción de la fuerza de trabajo. Incluso, en determinados momentos históricos, otorgó subsidios al consumo y estipuló precios de garantía para ciertos bienes y servicios básicos. Más aún, con la construcción de infraestructura básica y la provisión de servicios sanitarios y educativos, el Estado emprende cuantiosas inversiones públicas que lo convierten en el más grande agente consumidor de bienes, insumos y servicios necesarios para las burocracias que satisfacen y proveen dichos servicios básicos.

No menos importante es el papel del aparato de Estado en la administración de la demanda agregada y de la demanda efectiva, así como sus intervenciones ante los efectos negativos del ciclo económico y las crisis. Esto es, 
con instrumentos de política económica como la política fiscal y la política monetaria -adoptados desde los ministerios de hacienda y economía y desde los bancos centrales-, el aparato de Estado hace frente y contrarresta las tendencias de los ciclos económicos a través de la administración de la demanda y el diseño y ejercicio de políticas económicas anticíclicas que encaucen o atemperen las recesiones, las crisis o las depresiones económicas. A través de instrumentos cómo la política fiscal, la teoría económica keynesiana postula que es posible suavizar y estabilizar las fluctuaciones y oscilaciones drásticas del proceso económico y, con ello, equilibrar la balanza de pagos, estimular el crecimiento de la economía y el pleno empleo, y procurar la estabilidad de las principales variables macroeconómicas. Aunque el mecanismo de mercado, hasta cierto punto, coordina a los agentes económicos y, mediante el sistema de precios, facilita información para la toma de decisiones, los fallos del mercado pueden pronunciare a medida que se incurre en competencia imperfecta y en decisiones inadecuadas a partir de información limitada y sin calidad y cantidad suficientes. Por tanto, la política económica es el principal instrumento de intervención pública en el proceso económico en aras de estimular la eficiencia del mecanismo de mercado y corregir sus tendencias inherentes al desequilibrio. Con este instrumento, el aparato de Estado -según el momento histórico y la correlación de fuerzas- puede ser poseedor de medios de producción; también intervenir en la producción y/o consumo de insumos, bienes y servicios; e incidir en la reactivación de la demanda y en el fomento y estímulo de las acciones y decisiones de productores y consumidores para que ejerzan un activo papel en el proceso económico.

Retomando la metáfora del doble giro o movimiento introducida por Karl Polanyi (1992), ante la vocación y el carácter expansivo, destructivo y desbocado del mecanismo de mercado suscitados en un primer movimiento, la sociedad -en un segundo giro- tiende a organizarse políticamente para defenderse y contener, a través de diques (entramados institucionales) esa lógica que socava el tejido social, la cohesión y el sentido de comunidad. De ahí que el Estado sea la principal macroestructura con que cuenta la sociedad para defenderse de la lógica anárquica y desestructurante del mercado y de su consustancial individualismo; así como para construir redes de protección que propicien la reproducción de la fuerza de trabajo, generen cohesión social y legitimidad en torno al sistema político y el proceso de acumulación del capital. Por tanto, el Estado es un sistema orientado a la gestión y compensación -que no a la desaparición- de las desigualdades sociales agravadas por el carácter desequilibrado del mercado; además de atender la procuración de la estabilidad sociopolítica y la legitimación que son indispensables para el despliegue de la dialéctica desarrollo/subdesarrollo y el encauzamiento de sus contradicciones fundamentales. Más allá de la falaz oposición entre eficiencia económica y equidad social, las funciones 
redistributivas desplegadas por el Estado son fundamentales para el eficiente funcionamiento del mercado. Sin ellas, éste último se orientaría a satisfacer únicamente las necesidades del individualismo a ultranza y de los grupos sociales privilegiados, al tiempo que serían perpetuadas las desigualdades y contradicciones del capitalismo.

\section{DEL ESTADO DESARROLLISTA AL ESTADO MÍNIMO Y SITIADO POR LOS (CONTRA)PODERES FÁCTICOS: LA ENTRONIZACIÓN DEL FUNDAMENTALISMO DE MERCADO EN MÉXICO}

Las manifestaciones de la dialéctica desarrollo/subdesarrollo en un país como México, a lo largo del último siglo, estuvieron en función de la forma en que el capitalismo se arraigó en las relaciones sociales y tradujo en el territorio sus contradicciones, asimetrías y desequilibrios.

A grandes rasgos -aunque con las especificidades históricas que se presentaron y es necesario identificar y analizar de acuerdo a los cambios sexenales-, entre 1934 y 1985 las funciones del aparato de Estado en México consistieron en fungir como rector, regulador, planificador, promotor, inversionista, propietario de medios de producción, edificador de infraestructura básica e institucional, banquero y benefactor en la configuración de la dialéctica desarrollo/subdesarrollo. Inspiradas en la ideología del nacionalismo revolucionario -que en su camino interactuó con la ideología del desarrollo, el paradigma keynesiano/estructuralista y con las directrices de política pública propias del Banco Mundial-, las élites políticas mexicanas impulsaron con estas funciones un proceso de industrialización dirigida por el Estado para que fuese trascendido el modelo primario/exportador que predominó desde finales del siglo XIX. Este Estado desarrollista -que también se generalizó en vastos territorios del sur del mundo- se orientó a otorgar incentivos para la expansión del empresariado privado, las inversiones también privadas y para la acumulación de capital. Entre estos incentivos destacaron la adopción de mecanismos como tarifas arancelarias y no arancelarias, derechos de importación, subsidios para la importación de bienes intermedios y de capital, y límites al establecimiento de la inversión extranjera para la protección del mercado interno. Complementado ello con la adopción de políticas de fomento industrial; el establecimiento de tipos de cambio fijos y subvaluados; y el ejercicio de estrategias activas para que el sector público se erigiese en productor y proveedor de bienes y servicios que facilitaran la industrialización y la reproducción de la fuerza de trabajo.

El fin último de estas medidas se orientó a la estructuración de un régimen de economía mixta y a la transformación de la estructura productiva a partir del activo papel interventor del sector público. El crecimiento 
económico fue el eje central de las estrategias del Estado desarrollista y, a partir de su consecución, se asumió que el bienestar social derivaría por añadidura y de manera automática, pero se subordinaría a la acumulación de capital. De esta forma, entre 1934 y 1980 se edificó una amplia infraestructura física y social que se acompañó de instituciones también creadas en esas décadas y que se orientaron a la construcción de mercados y a definir formas específicas de distribución de la riqueza. A partir de la segunda mitad de la década de los cuarenta, este Estado desarrollista fundamentado en un régimen corporativo/clientelar alcanzó su auge, pero hacia 1968 las movilizaciones de la clase media cuestionaron sus fundamentos políticos y los efectos negativos de sus estrategias de desarrollo. Esto es, pese a las altas tasas de crecimiento del Producto Interno Bruto y la estabilidad de precios, tendían a perpetuarse -en el contexto de un sistema político presidencialista autoritario y de partido hegemónico- las debilidades estructurales, los desequilibrios regionales, las asimetrías del campo respecto a la ciudad, la exclusión social y la expansión del México marginal (un estudio certero y creativo sobre las contradicciones del sistema político mexicano lo ofrece González Casanova, 1975).

Sin embargo, hacia finales de la década de los sesenta y durante toda la década de los setenta, el rezago del campo, la baja productividad y competitividad del aparato productivo, así como el endeudamiento externo y la dependencia tecnológica y financiera, coincidieron con la crisis estructural del capitalismo y con la recesión de la economía mundial experimentadas hacia 1973. Este escenario sentó los cimientos de la crisis del Estado desarrollista y de su crisis fiscal que tocaría fondo con la expansión del gasto público deficitario y la bonanza petrolera, que -en su conjunto- prolongaron unos años más las estrategias proteccionistas e intervencionistas, hasta precipitarse la crisis de la deuda en 1982 y el consecuente viraje en el perfil de las funciones del Estado mexicano.

Las transformaciones estructurales suscitadas con los condicionamientos impuestos por la crisis de la deuda y su proceso de renegociación a lo largo de la década de los ochenta, condujo a México a un intenso proceso de ajuste y cambio del modelo económico que colocó al Estado en el epicentro. La mayor incidencia del llamado Consenso de Washington en las políticas públicas mexicanas, indujo la transición del aparato de Estado desde su posición de activo agente económico -teniendo a la inversión pública como palanca del crecimiento de la economía- y decidido rector y promotor del desarrollo hacia funciones de convocante, gestor, facilitador, publicista y compensador de la inversión privada -particularmente de la inversión extranjera directa-, así como de las exportaciones manufactureras. A su vez, con estas transformaciones orientó sus instrumentos de intervención a generar un entorno institucional (business environment en el 
lenguaje del Banco Mundial, 1997, 2001 y 2004) propicio para el despliegue del proceso económico liderado por el empresariado privado. El acotamiento y retracción experimentado, desde 1985, por el sector público respecto al conjunto del proceso económico devino en la expansión y fortalecimiento de la iniciativa privada, especialmente de los capitales extranjeros y de aquellos sectores del empresariado nacional vinculado a los sistemas internacionales de producción integrada, a los encadenamientos mercantiles mundiales y a las redes financieras globales. Este proceso significó un vaciamiento de la capacidad del Estado mexicano para tomar decisiones económicas estratégicas y ejercer la soberanía económica; acercando a éstas a una transnacionalización capturada y condicionada por los agentes de los mercados financieros, las redes empresariales globales y por aquellos organismos internacionales que ejercen una mayor gravitación y teledirección en materia de política económica.

Esta reorientación de las funciones estatales en la dialéctica desarrollo/ subdesarrollo supone el ejercicio de una selectiva, desarticulada, pasiva y compensatoria intervención del sector público en cuanto a la construcción de mercados y la (re)distribución de la riqueza. Ello no solo redundó en el fortalecimiento del empresariado privado y en la expansión de la inversión extranjera como motor del crecimiento económico, sino también en la proliferación de fuerzas, actores y agentes que le disputan al Estado el poder y el control del territorio.

La racionalidad del renovado Estado mexicano no lo fue más el mercado interno y sus encadenamientos productivos; ni orientó la construcción de instituciones y de infraestructura básica a ello. Más bien, la economía mundial se erigió en la nueva racionalidad de las decisiones públicas. De ahí que desde 1988, las políticas públicas se orientasen a la construcción, proyección, gestión y legitimación de la integración de la economía mexicana en los sistemas internacionales de producción integrada y en las redes financieras globales. En este sentido, el aparato de Estado -acotado en su poder económico y en sus mecanismos de intervención- se despojó de la maquinaria corporativo/clientelar encarnada en el partido cuasi oficial en aras de un perfil organizacional flexible que no obstaculizase la inserción actualizada de México en los circuitos de la economía global. Estas intervenciones acotadas, selectivas, compensatorias e, incluso, débiles, erráticas y hasta nulas, se correspondieron con la desincorporación y privatización de empresas públicas, y la posterior transferencia de activos estratégicos que vació al sector púbico de su poder económico y territorial. Así, el empresariado privado transnacional acrecentó los alcances de su poder y se posicionó en sectores estratégicos como la construcción de infraestructura, la banca comercial, los ferrocarriles, la petroquímica, los medios masivos de difusión, las telecomunicaciones, la aviación comercial, entre otros. 
En este sentido, el aparato de Estado orienta sus reconfigurados entramados institucionales a esa renovada racionalidad tras apuntalar el ejercicio de una vocación geoeconómica y geopolítica para insertar -si bien de manera subordinada y generando desarticulaciones endógenas-a México en la dinámica propia de la expansión e integración global del capitalismo en condiciones de cierta legitimidad y relativa estabilidad sociopolítica que garanticen la valorización y acumulación de capital.

Este achicamiento del poder económico del sector público se ciñó al imperativo de la disciplina fiscal y del equilibrio de las principales variables macroeconómicas, aún a costa de estrangular el aparato productivo, inhibir el crecimiento económico y la creación de empleos. Encaminando con ello a la economía nacional a una especie de estancamiento estabilizador (para mayores detalles sobre esta tendencia véase Huerta González, 2004). El fin último de esta renovada orientación de la política económica consistió en crear condiciones de certidumbre a las decisiones, inversiones y transacciones del empresariado privado y los mercados financieros; recurriendo para ello a las estrategias de estabilización macroeconómica, redefinición y adecuación de la regulación económica, privatización, y apertura de la economía nacional.

Sin embargo, estas políticas deflacionarias adoptadas en México desde la década de los ochenta, mostraron sus efectos negativos hacia los años noventa Entre estos destacan la erosión sistemática de las políticas de industrialización, el desmantelamiento del aparato productivo nacional, el desvanecimiento del tejido empresarial nativo, y la conversión de la inversión productiva en capitales especulativos (sobre los efectos negativos de estas políticas económicas consúltese Cárdenas, 1996; Calva, 1999, 2008 y 2000; Guillén Romo, 2000 y 2012; Huerta González, 2004 y 2016; Grupo Nuevo Curso de Desarrollo, 2012).

Más aún, las referidas estrategias de política económica redundaron en la profundización de la desnacionalización integral (concepto introducido, mediante una destacada elaboración teórica, por Saxe-Fernández, 1988) tras erosionarse el control y gestión del proceso económico. Inspiradas en el supuesto de la «espontaneidad del mercado», las élites tecnocráticas que controlaron el aparato de Estado desde 1985 concibieron a este mecanismo como fundamento del crecimiento económico y la libre competencia. Incuso lo asumieron como un credo incuestionable que raya en el fundamentalismo. Sin embargo, el posicionamiento de los capitales extranjeros en los sectores estratégicos y la transnacionalización -en un escenario de acuciante crisis institucional- de las decisiones económicas, acentuó esta desnacionalización integral; la cual se expresó en una erosión del poder y potestades del sector público en materia de toma de decisiones estratégicas relacionadas con el proceso económico. Esto es, el desmantelamiento de las históricas funciones 
rectoras, intervencionistas, promotoras y reguladoras de la economía; la acelerada e irrestricta apertura comercial; y la privatización y extranjerización de activos como los bancario/financieros y amplias franjas del aparato industrial, cuestionan los imperativos de la soberanía económica; al tiempo que posicionan a las redes globales de toma de decisiones - de las cuales forman parte, de manera comprometida, esas élites tecnocráticas- en la hechura de la política económica y el diseño de los presupuestos públicos.

Más todavía, la reorientación de las funciones estatales en la dialéctica desarrollo/subdesarrollo y el perfilamiento de un Estado mínimo tienen como trasfondo una crisis de lo público que alcanza una de sus expresiones en la falta de legitimidad y en la incapacidad del Estado mexicano para articular y cohesionar a los poderes fácticos -sean socioeconómicos o políticos-que le disputan la hegemonía y el control del territorio. Actores y agentes como el empresariado privado nacional y extranjero, el alto clero, los medios masivos de difusión, los individuos que imponen «justicia por mano propia», y las organizaciones criminales - con el acotamiento y reconfiguración de las funciones del Estado-, se erigieron durante las últimas décadas en frontales poderes y contrapoderes fácticos que vieron crecer su autonomía e influencia económica, política y simbólico/cultural. No solo rompieron las reglas no escritas que les disciplinaban en el antiguo sistema político, sino que también tendieron a desafiar, subvertir, depredar y subordinar a las instituciones estatales. La expansión de esos poderes fácticos -que incluso en vastos territorios del país imponen una especie de parainstitucionalidad estatal-se correspondió con la incapacidad del sector público para fomentar y garantizar el crecimiento económico, la (re)distribución de la riqueza, la seguridad pública, la preservación de la integridad física de los ciudadanos, y la procuración de la justicia.

Esto significa que el Estado -en esta transformación histórica de sus funciones esenciales- fue vaciado de legitimidad, de contenido programático y de aquel proyecto de nación suscrito en la Constitución Política de 1917; y, a su vez, vio erosionado el ejercicio de su soberanía y la posibilidad de articular y cohesionar a la sociedad, a los distintos grupos sociales dotados de intereses creados, y al territorio. Ello se explica, en buena medida, porque los mecanismos, reglas no escritas y prácticas corporativo/clientelares entre el Estado y la sociedad dejaron de ser funcionales al ejercicio del poder político y al proceso de acumulación de capital cada vez más transnacionalizado y necesitado de organizaciones flexibles. A su vez, las decisiones públicas incluidas las negociaciones en lo obscurito para construir mecanismos de poder y otros arreglos políticos- no son aceptadas ni legitimadas unánimemente por los poderes y contrapoderes fácticos y los grupos de presión que se expanden incontroladamente por el territorio y tienden a depredar las instituciones y el espacio público. 


\section{EL ESTADO MEXICANO Y LOS INTERSTICIOS DE LA PLANEACIÓN DEL DESARROLLO: ENTRE LOS ESPACIOS GLOBALES PARA LA TOMA DE DECISIONES Y LOS PROBLEMAS PÚBLICOS LOCALES/NACIONALES}

Las decisiones públicas y el ejercicio del proceso de planeación, si bien son potestades del Estado, éstos no se encuentran exentos de la gravitación desplegada por fuerzas, factores, circunstancias y agentes exógenos que -conformando escenarios relativamente autónomos respecto a las necesidades nacionales- pretenden incidir en la agenda pública y en el cauce que adopte la dialéctica desarrollo/subdesarrollo. Particularmente, se suscita una relación orgánica entre las élites políticas que dirigen al Estado y los actores y agentes que le dan forma a espacios globales para la toma de decisiones; sin que ello suponga una imposición vertical, y sí una compenetración y un compromiso estrecho entre ambos.

En principio y tal como se estudió en otros productos de investigación (Enríquez Pérez, 2010 y 2017), los organismos internacionales son esos sistemas abiertos e intergubernamentales dotados de un relevante poder epistémico y de atribuciones o facultades derivadas del despliegue de labores de formación de recursos humanos y de asistencia técnica y financiera, que -en su conjunto y a través de una capacidad de teledirección-inciden y configuran la armonización, sincronización, homogeneización, estandarización, convergencia y coordinación de las políticas públicas que, en el escenario de las últimas tres décadas, perfilan una necesaria institucionalidad global que acompaña a los mercados y a un sinfín de problemas públicos que tienen orígenes y manifestaciones también globales. Desde esas organizaciones interestatales se diseñan, estipulan y difunden directrices y pautas de comportamiento que ofrecen luz en torno al debate que se abre para el diseño y ejercicio de políticas públicas nacionales. Más aún, desde los organismos internacionales se instalan temáticas que son definidas como problemas públicos y, a partir de las cuales y bajo ciertos enfoques, se esbozan posibles soluciones y se trazan directrices, pautas normativas y cursos de acción a introducir en sus estrategias de política pública por parte de los gobiernos nacionales, así como en la configuración de la agenda pública en temas variados como la política económica, la política comercial, las relaciones laborales y sus legislaciones, la política educativa, la política social, el medio ambiente, los derechos humanos, la salud pública, el desarrollo urbano y territorial, la gobernabilidad, entre otras.

A partir de esa relación orgánica que se teje de manera compenetrada entre las élites políticas nacionales y los funcionariados internacionales, comienza a configurarse la constelación de espacios globales para la toma de decisiones. En principio, los códigos de comunicación, las conductas, el 
tipo de pensamiento y la formación académica de los funcionarios nacionales de alto y mediano nivel que laboran en ministerios estratégicos capaces de controlar las directrices generales de la agenda pública, conforman -no siempre en circunstancias de igualdad-comunidades epistémicas trans-territoriales con las burocracias y cuerpos técnicos altamente calificados de los organismos internacionales. Estas comunidades epistémicas trans-territoriales se extienden y se nutren de capacitadores, consultores, asesores y académicos que laboran en universidades globales y que poseen sistemas teórico/ conceptuales que delinean cursos de acción y concepciones sobre los problemas públicos; directivos y expertos de Think Tank's privados, agencias calificadoras y cabilderos de intereses empresariales y financieros; activistas, líderes y técnicos de influyentes Organizaciones No Gubernamentales Internacionales (ONGI); grupos de presión (empresariado, agentes financieros, iglesias); y líderes de opinión que difunden cierto tipo de mensajes relacionados con los problemas públicos a través de las industrias culturales globales. Desde esta concurrencia de intereses y formas de concebir la realidad social y sus problemáticas se estructuran los referidos espacios globales para la toma de decisiones. Cabe destacar que -pese a las diferencias y disputas- en esta red existe una alta cohesión social y que las identidades grupales y el capital social se perfilan sobre la base de compromisos, intereses creados, cosmovisiones y sistemas teórico/conceptuales, ý códigos de comunicación compartidos que definen idiosincrasias, conductas y posicionamientos ante las decisiones públicas.

En este escenario, el Estado -especialmente en el mundo subdesarrollado- es condicionado en materia de planeación por esa teledirección irradiada desde los espacios globales para la toma de decisiones a partir de las dosis de poder, los conocimientos especializados y los contactos políticos poseídos por los actores y agentes de la red que pretenden posicionar y hacer valer sus intereses creados, cosmovisiones e ideologías en el marco de las negociaciones internacionales y del despliegue de la diplomacia del desarrollo.

De este modo, con la intensificación de los procesos de globalización y la diseminación planetaria de masivos flujos comerciales, monetarios, simbólico/culturales, informacionales, de personas -incluidos migrantes indocumentados-, riesgos y violencia criminal, se erigen «agujeros negros» que escapan al control y fiscalización del Estado. De ahí que la planeación y la configuración de la agenda pública orientadas a responder a los problemas públicos de los espacios locales/nacionales están también en función de los condicionamientos y limitaciones que irradian de las políticas públicas y las acciones gubernamentales concretas adoptadas en otros países y también negociadas y consensuadas en esos mismos espacios globales. Como parte de todo lo anterior, la noción tradicional de soberanía nacional es trastocada 
y redefinida e, incluso, la autonomía de las políticas públicas es socavada con la expansión de las relaciones estratégicas entre el mercado, el Estado y demás actores socioeconómicos. Si la globalización refiere a la interacción entre presencia y ausencia, o a relaciones sociales transplanetarias que se producen sin que los actores se encuentren presentes físicamente en el espacio local donde se concretan, una relación estratégica se configura con las decisiones y acciones tomadas y ejercidas por un agente o que ocurren en determinado mercado y que, derivado de ello, gestan efectos y consecuencias en otras latitudes y sociedades que se localizan a miles de kilómetros de distancia. De ahí la trascendencia de la armonización, sincronización, estandarización, homogeneización, convergencia y coordinación de las políticas públicas a escala global; así como de los condicionamientos a los cuales está expuesto un Estado en el ámbito de la planeación y del curso que adopta la dialéctica desarrollo/subdesarrollo, de cara a la transcontinentalización y la mayor densidad o velocidad de las relaciones sociales.

Como en las naciones subdesarrolladas - pensemos en México- no se concreta una autonomía plena en torno a lo que deben ser los problemas públicos y las posibles soluciones encaminadas a ellos, las políticas públicas y las funciones del Estado que de esos instrumentos se desprenden están expuestos a ideologías y a sistemas teórico/conceptuales preñados de etnocentrismo, así como a una asimilación mecánica y acrítica de concepciones distantes y ajenas a la realidad de esas naciones subdesarrolladas. Más aún, es de destacar que la planeación del desarrollo es influida por las decisiones $\mathrm{y}$ acciones de actores y agentes que no necesariamente son parte del espacio local/nacional, así como por la expansión de mercados que no son controlados ni mínimamente por retraídos gobiernos nacionales como el mexicano que ejercen intervenciones selectivas, precarias y débiles -e incluso nulasen el proceso económico y en la vertebración de la sociedad en general. Además, las políticas públicas y las decisiones que entrañan tienden a ser más receptivas y sensibles a los vertiginosos cambios y comportamientos de las interdependientes relaciones internacionales, sobre todo porque la economía mundial y la política internacional se posicionan como las nuevas racionalidades de la agenda pública. La misma acción de los actores y agentes gubernamentales y el perfil de las políticas públicas que la orientan, están en función de los acontecimientos, dinámica y decisiones suscitadas en otras naciones y espacios locales influyentes y capaces de articular y posicionar sus concepciones, ideologías e intereses en el debate público internacional y estandarizarlos en documentos estratégicos diseñados y difundidos por los organismos interestatales.

Particularmente, en el caso de México, desde el fin de la Segunda Gran Guerra, el Estado desempeñó un destacado papel en la configuración de la constelación de organismos internacionales que por aquellos años se 
edificaba. El mismo diseño de las políticas públicas en este país está influido por factores y agentes externos, entre los cuales destacan las organizaciones intergubernamentales y su capacidad para teledirigir el proceso de planeación, la construcción de mercados y la redistribución de la riqueza. Entre estas organizaciones y el Estado mexicano se construyen relaciones orgánicas a partir de ciertas Convenciones, Cumbres, Conferencias, Asambleas Generales y Reuniones Anuales convocadas por los primeros y suscritas por las representaciones nacionales. En dichos eventos se estipulan normas, convenios, acuerdos, declaraciones, resoluciones, protocolos y pactos que, al ser suscritos por los Estados miembros participantes, afectan las decisiones públicas tomadas en el seno de sus gobiernos y órganos legislativos que deliberan en torno a la incorporación de estos factores exógenos. La Convención Marco de las Naciones Unidas sobre Cambio Climático, la Conferencia Mundial de Derechos Humanos, los Decenios de las Naciones Unidas para el Desarrollo, la Declaración del Milenio, los Objetivos de Desarrollo Sostenible y la Agenda 2030, son algunos ejemplos de cooperación internacional liderados por organismos internacionales y que tienden a perfilar y/o modificar pautas de decisión y acción en las administraciones públicas nacionales. En estos eventos y documentos se delinean cursos de acción, comportamientos y normas para regular gran cantidad de temas relativos a la gestión de la dialéctica desarrollo/subdesarrollo. Lo cual, sin duda, modifica y condiciona la toma de decisiones en los ámbitos nacionales y encauza la orientación del poder ejecutivo y de los órganos legislativos, pues en última instancia todo cambio estructural y materialización de política pública atraviesa por un proceso de reformas en las estructuras jurídicas que, en primer lugar, se estipulan como norma jurídica en una Constitución Política o en Leyes Secundarias y -a partir de ello- se estandarizan los lineamientos, funciones y acciones del sector público en el proceso económico, la construcción de mercados, la distribución de la riqueza, la procuración de justicia, la provisión de servicios sociales, la gestión y regulación de los mercados laborales, la reivindicación de los derechos humanos, el manejo de las desigualdades sociales, el ejercicio de la gobernabilidad, los procesos de democratización, entre otros.

Si bien existen estos condicionamientos exógenos y las funciones del Estado se exponen a la cesión de importantes porciones de soberanía en la formación de regímenes internacionales, son preservadas decisiones, potestades y facetas estratégicas bajo su jurisdicción. Más todavía, pese a la dispersión de las decisiones estratégicas y a la reconfiguración de la soberanía que cada vez tiende a compartirse de manera acentuada con entidades supranacionales, los aparatos de Estado desempeñan funciones cruciales y cada vez más complejas en la construcción de los mercados mundializados y en torno a varias facetas de la globalización y a la necesidad de hacer funcionales las desigualdades sociales y demás efectos negativos derivados de la 
expansión e integración global del capitalismo. De ahí la importancia de analizar estas funciones renovadas del Estado mexicano, derivadas de los referidos cambios históricos y de la correlación de fuerzas interna y externa.

\section{LA RECONFIGURACIÓN DE LAS FUNCIONES DEL ESTADO MEXICANO DE CARA A LA CRISIS INSTITUCIONAL Y EL AHONDAMIENTO DE LAS CONTRADICCIONES DEL CAPITALISMO PERIFÉRICO}

La transformación de las funciones del Estado mexicano desde la década de los ochenta marcha paralela al agotamiento del Estado desarrollista, a la gestación y agravamiento de la crisis institucional, y a la desventajosa y asimétrica inserción actualizada de la economía nacional en la lógica propia de la expansión e integración global del capitalismo.

El carácter contradictorio de la dialéctica desarrollo/subdesarrollo, relacionado con las formas que adquieren las transformaciones estructurales y organizacionales del capitalismo en un país como México -tal como se introdujo en apartados anteriores-, perfiló nuevas funciones del Estado mexicano en torno a la construcción de mercados y la distribución de la riqueza. Esta transformación de las funciones estatales, redefinió también a sus actores, agentes, instituciones, organizaciones y a sus instrumentos de intervención, profundizando los mecanismos de poder y reconfigurando las políticas públicas que posibilitan las condiciones para la consolidación de la expansión e integración global del capitalismo y para la reinserción de México a esta lógica. A su vez, las políticas públicas expresan las tendencias delineadas por esas transformaciones e, incluso, con ellas se apuesta al apuntalamiento de los espacios globales para la toma de decisiones y de la red hegemónica global.

A partir de los indicadores rastreados en las políticas públicas diseñadas y adoptadas durante los últimos 35 años (Poder Ejecutivo Federal, 1983, 1989, 1995, 2001, 2007 y 2013) y su entrelazamiento con las directrices de organismos internacionales-, es posible observar las siguientes funciones que delinean un nuevo perfil del Estado mexicano; a saber: a) la procuración y gestión de la estabilidad y los equilibrios macroeconómicos; b) el ejercicio de una vocación (o la reorientación) geopolítica y geoeconómica que promueve la integración de México en la economía global; c) la promoción, gestión y facilitación de la inversión privada -sobre todo de la extranjera- y de las exportaciones de manufacturas maquiladas; d) la configuración de entornos institucionales para la construcción de mercados y el despliegue de las transacciones económicas; e) la democratización del sistema político mexicano y la construcción de mecanismos de legitimidad para la élites políticas y el modelo económico; y f) el ejercicio de un nuevo asistencialismo social 
para el empoderamiento de las comunidades locales marginadas y la compensación -mediante una política social focalizada- de los efectos sociales negativos derivados de la adopción de la política económica. Cabe matizar que no se reconoce que en México se cumpla a cabalidad con una de las funciones por antonomasia de los aparatos de Estado: aquella relacionada con la posesión del monopolio legítimo de la violencia y la salvaguarda de la vida, la integridad física y el patrimonio de los ciudadanos; es decir, la procuración de la seguridad pública y el encauzamiento del conflicto social por senderos institucionales que redunden en el imperio de la ley. El incumplimiento de esta función es precisamente lo que abre las múltiples vertientes de una crisis institucional en el país.

Decimos que esta función del aparato de Estado en tanto «guardián o custodio» no se realiza plenamente en México debido, en buena medida, a que no garantiza su poder y control del territorio ante los particulares y a que el país es sitiado, con mayor intensidad desde 1994, por la delincuencia organizada que estructura una economía criminal -nos referimos a actividades delictivas como el secuestro, la extorción, el cobro de derecho de piso y el narcotráfico- de amplias magnitudes que se extiende exponencialmente por el tejido social y que genera un estado de tensión permanente y de violencia que escapa a todo control de la autoridad. Cabe mencionar que la eficacia con que operan estas organizaciones criminales es mayor que la desplegada por las mismas burocracias públicas en el cobro de impuestos, la procuración de justicia y en el control del territorio. Esta debilidad del Estado se evidencia también con los feminicidios masivos de mujeres en variados puntos del país; los miles de desaparecidos y ultimados a manos del crimen organizado; los centenares de cadáveres que no logran identificarse; las turbas violentas que procuran e imponen -a través de los linchamientos- «justicia por mano propia» y que expresan enormes vacíos institucionales y policiales; el tráfico de migrantes; y con la creciente impunidad y corrupción que permea en la administración pública y que imposibilita la oportuna, expedita y eficaz procuración de justicia.

Este escenario signado por la violencia generalizada y el limitado control de las instituciones públicas sobre (contra)poderes fácticos (narcotraficantes, extorsionadores, secuestradores, traficantes de armas, combustibles y personas, etc.) que -especialmente desde el año 2006-radicalizan su fuerza, recursos y acciones (piénsese en los narcobloqueos, el secuestro y asesinato de periodistas y líderes políticos, la profundización de la lucha entre grupos criminales por el control del territorio y los mercados de narcóticos, desapariciones forzosas, homicidios dolosos que alcanzan el rango de epidemia, etc.), colocando a la población en una situación de indefensión, abandono y vulnerabilidad, e incluso a la misma élite política que es afectada -directa e indirectamente- en su integridad física por el crimen organizado, sugiere la 
gestación de una crisis de Estado caracterizada por la erosión y depredación de los entramados institucionales, la cohesión comunitaria y el capital social. Complementado ello por una escasa legitimidad de los grupos gobernantes empeñados en socavar y vaciar de contenido a las instituciones a través de la corrupción, la impunidad y el uso patrimonialista de lo público. Se trata de una causalidad circular, en la cual la debilidad de la cohesión social y el desdén respecto a la ley y lo público, generan condiciones propicias para la germinación de grupos sociales -algunos excluidos de la economía formal; otros deseosos de la consolidación de su poder y riqueza- capaces de disputarle al Estado el monopolio de la violencia y de hacer del crimen organizado una actividad asimilada, «naturalizada» y arraigada en la sociedad. Al tiempo que estos efectos provocan y profundizan la creciente descomposición social y eclipsan los alcances de la presencia y poder del Estado en sus esfuerzos para la estructuración de la sociedad.

Cabe señalar que masivos sectores de la población mexicana experimentan una situación de exclusión social y abandono por parte del Estado que aunada a la ancestral y persistente desigualdad social y económica-, crean el caldo de cultivo para la expansión de las actividades criminales y su «normalización» en vastos territorios del país. El crimen organizado - ante la ausencia de proyectos de desarrollo en las comunidades y el enraizamiento de contactos institucionales que reducen los riesgos de sanción penal para los criminales- se convierte en una alternativa económica y un estilo de vida viable para amplios contingentes excluidos del sistema económico y político. Este abandono de la población excluida por parte del Estado evidencia la entronización del fundamentalismo de mercado y la erosión sistemática de una de sus funciones básicas: la referida a la reducción de las brechas de la desigualdad social.

Realizada esta digresión, analizamos cada una de las seis funciones estatales identificadas desde 1985 hasta la actualidad.

a) El aparato de Estado como garante de la prioritaria estabilidad macroeconómica. Con las espirales inflacionarias, el desequilibrio externo y la crisis de la deuda gestados a inicios de los años ochenta en México, se observa en los instrumentos de política económica -y, particularmente, en la política monetaria del Banco de México- un acentuado interés por la contención del nivel de precios, el equilibrio de la balanza de pagos y la reducción del déficit fiscal. Dimensiones éstas que son asumidas como condiciones básicas para procurar la estabilidad macroeconómica.

Frente a ello, cabe cuestionarse lo siguiente: ¿Por qué se presenta en las políticas públicas y en las declaraciones de las élites tecnocráticas una preocupación - hasta cierto punto obsesiva- por el abatimiento de la inflación? La respuesta se relaciona con la promoción y procuración de condiciones 
macroeconómicas adecuadas para el ejercicio de las actividades del empresariado privado y para la mayor captación de sus inversiones. Esto significa que si no se cuenta con una inflación baja y estable, tanto en las empresas como en los mercados financieros serán afectados los marcos de decisión relativos a la producción, consumo y financiamiento; al tiempo que los riesgos y la incertidumbre aumentarán para esas inversiones. La estabilidad de precios resulta relevante para los inversionistas porque les permite calcular los costes y ejercer la adecuada toma de decisiones; de lo contrario, corren el riesgo de sufrir pérdidas.

Al erigirse la economía global como la nueva racionalidad y el punto de referencia central de los agentes económicos y sus decisiones, para los promotores de las estrategias de estabilización y apertura es relevante contar con un posicionamiento ventajoso a través de la estabilidad de la balanza de pagos. Por ello, se esboza la prioridad de promover una industrialización orientada hacia las exportaciones bajo el argumento de que estas transacciones incentivan la productividad y, por tanto, el crecimiento económico. La estabilidad macroeconómica y las intervenciones selectivas del aparato de Estado para facilitar las condiciones y el entorno propicios a las actividades y transacciones del empresariado privado con vocación exportadora, son cruciales para el afianzamiento de la estrategia de apertura de la economía mexicana.

También se argumenta que el abatimiento del déficit fiscal se relaciona con el reordenamiento, racionalización, modernización y privatización del sector público en aras de contar con intervenciones selectivas más eficaces, corregir los fallos del Estado y eliminar las distorsiones en los mercados. Con esta medida, son dos los instrumentos del aparato de Estado que más se modificaron, al tiempo que se redefinen sus funciones y responsabilidades en general: el gasto público, sujeto a constantes recortes y a ejercicios de racionalización con el objetivo de contar con finanzas públicas sanas; y la procuración -cuando menos hasta el año 2000- de un menor endeudamiento público. Esto es, con el gasto público reducido tienden a focalizarse las intervenciones estatales y a recurrir lo menos posible a un financiamiento deficitario que incentive la inflación tras persistir una oferta monetaria que sobrepase los niveles de producción de la economía nacional. En tanto que en el mismo presupuesto público se adopta la postura de responder a las urgencias impuestas por el servicio de la deuda.

A grandes rasgos, las estrategias de estabilización, redefinición y adecuación de la regulación económica, privatización y apertura de la economía nacional adoptadas desde los años ochenta en México, responden a las exigencias de la estandarización, homogeneización, armonización, sincronización, convergencia y coordinación de políticas económicas que derive en certidumbre y en la generación de confianza en el país entre los inversionistas 
extranjeros, la banca comercial privada mundializada, las agencias calificadoras del riesgo-país y los organismos financieros internacionales. Sin esta función estatal que consiste en procurar los equilibrios macroeconómicos y en generar condiciones y entornos propicios para el desenvolvimiento del proceso económico, serían imposibles los periodos de auge, estabilidad y abandono de las crisis.

b) La reorientación de la propensión geopolitica y geoeconómica para facilitar la integración de México en la expansión global del capitalismo. Gran parte de las políticas públicas diseñadas y ejercidas por el aparato de Estado en México desde 1986 responden a las necesidades marcadas por la intensificación de las relaciones interestatales y comerciales. Dos acontecimientos acentuaron esta tendencia: el ingreso de México al GATT en 1986, hecho que marcó la pauta para emprender a fondo las estrategias de apertura de la economía nacional; y la emergencia de nuevos regionalismos y procesos de integración económica en Europa y el Este de Asia. Ambas circunstancias incentivan en México la firma de acuerdos y tratados comerciales, el ingreso a bloques regionales y el diseño de políticas públicas de alcance transnacional.

Con esta reorientación de la función geopolítica y geoeconómica, se privilegia en las políticas públicas y en las intervenciones estatales una concepción estratégica del territorio y de su aprovechamiento en el proceso económico y en la expansión global del capitalismo. El control, dominio y explotación del territorio en tanto fuerza productiva estratégica para la valorización y acumulación del capital se expresa tanto en la integración de bloques comerciales - por ejemplo, el emanado del ahora cuestionado y renegociado Tratado de Libre Comercio de América del Norte (TLCAN)como en el diseño, difusión y ejercicio de políticas públicas nacionales de alcance sectorial -el Programa Nacional de Desarrollo Urbano 1995-2000 (Enríquez Pérez, 2002) y el Programa Nacional de Desarrollo Urbano y Ordenación del Territorio 2001-2006-, o de corte transnacional -el Plan Puebla-Panamá y las Iniciativas Mesoamericanas- (Enríquez Pérez y Flores Sandoval, 2002; Torres Torres y Gasca Zamora, 2006).

A los territorios locales, y en especial aquellos que se encuentran en reserva -pensemos en los del Sur-Sureste mexicano-, se les asume como recursos escasos con dimensiones dinámicas para la integración activa en la expansión de los procesos globales a través de vías como: la producción y abastecimiento de materias primas; las capacidades empresariales; la mano de obra masiva y barata; los mercados poco explotados; el acceso al sistema urbano nacional; los conocimientos tradicionales -tanto productivos como medicinales-; la privilegiada posición geoestratégica para el desplazamiento de los flujos comerciales; los asentamientos humanos contendores de la 
migración hacia el norte; y los espacios poco utilizados que se convierten en reservas necesarias para la reproducción del capital en los sistemas internacionales de producción integrada y los encadenamientos mercantiles globales impulsados por las redes empresariales bajo la adopción de los sistemas de manufactura flexible (véase Torres Torres y Gasca Zamora, 2006; Enríquez Pérez, 2011).

Esta incorporación y reconversión de espacios inéditos que fungen como reservas territoriales y asentamientos poblaciones rurales con economías de autoconsumo, se proyectan e impulsan con la finalidad oficial de crear entornos y condiciones propicios para la generación de vocaciones territoriales a partir del aprovechamiento de su localización estratégica; la disponibilidad de recursos naturales abundantes; y su posible acondicionamiento para la construcción de infraestructura básica que permita la atracción de inversiones, los flujos comerciales y la integración de las regiones a los circuitos transnacionalizados de producción y consumo -el Istmo de Tehuantepec, la Riviera Maya, la sierra de los Chimalapas, el Corredor Biológico Mesoamericano, etc., son muestra de ello- (véase Presidencia de la República, 2001).

Por su parte, con bloques regionales como el constituido con el TLCAN, se propuso utilizar la posición geoestratégica privilegiada que posee México en el contexto internacional y en las rivalidades interbloque. Se buscó también una profundización mayor de las estrategias de apertura que orientan la economía nacional hacia el exterior con mayor intensidad desde 1986, así como un posicionamiento adecuado -aunque en los hechos muchas veces desventajoso-, a partir de la generación de las ventajas comparativas y competitivas, en los sistemas internacionales de producción integrada, los encadenamientos mercantiles mundiales, las redes financieras globales y en los cada vez más intensos procesos de armonización, estandarización, convergencia, sincronización, homogeneización y coordinación de políticas económicas que se promueven en los espacios globales para la toma de decisiones.

En suma, tanto las políticas públicas -incluidas las llamadas reformas estructurales- como porciones importantes del gasto público, y en general buena parte de las decisiones y funciones estatales, se canalizan al estímulo de una intensa inserción de México en las circunstancias planteadas por los procesos de integración regional y global. Las estrategias de estabilización, redefinición y adecuación de la regulación económica, privatización y apertura que fomentan la orientación de la economía mexicana hacia el comercio exterior; el fortalecimiento del empresariado privado -sobre todo del transnacional ubicado en el país - en detrimento del aparato productivo nacional; la generación de condiciones institucionales y macroeconómicas propicias para el establecimiento de la inversión; la atracción de divisas a través de la promoción turística, entre muchas otras acciones estatales, lo evidencian abiertamente. 
c) La promoción, gestión y facilitación de la inversión privada. Otra de las destacadas funciones del aparato de Estado -incluidos los gobiernos de las entidades federativas y los municipios- en torno a la dialéctica desarrollo/ subdesarrollo consiste en la convocatoria de flujos de inversión privada; en especial de capitales extranjeros que son parte del sistema de la manufactura flexible orientado a privilegiar ciertos territorios y no otros. Como parte de la estrategia de apertura de la economía nacional, en el marco de la expansión de los sistemas internacionales de producción integrada, para el estímulo a la inversión extranjera directa, tanto la generación y fortalecimiento de condiciones macroeconómicas e institucionales propicias, como el cultivo de mínimas vocaciones territoriales locales para la atracción y establecimiento de esos capitales, son consideradas dos prioridades básicas en las políticas públicas globales, sectoriales, regionales y/o locales. Más aún, en el marco del fortalecimiento del empresariado transnacional en detrimento del poder económico del sector público, a la inversión privada se le concibe en los documentos oficiales como un importante motor en la generación de empleo, el aumento de la productividad, la construcción y modernización de infraestructura, y en el estímulo del crecimiento económico.

Como parte de las intervenciones selectivas, esta función de convocante y facilitador adoptada por el aparato de Estado se expresa en actividades de diplomacia, marketing y promoción que publicitan las vocaciones territoriales del país y de ciertos espacios locales en particular; en la gestión para la atracción y establecimiento de las inversiones y para la negociación o renegociación de tratados y acuerdos comerciales que las mantengan, intensifiquen y regulen; así como en la construcción de infraestructura carretera, portuaria, aeroportuaria y de telecomunicaciones que posibilite el despliegue, viabilidad y rentabilidad de la inversión productiva.

De este modo, de contar con una política industrial y de ser un agente económico activo y propietario de los medios de producción, el aparato de Estado transitó a una función de convocante, publicista, promotor, gestor y facilitador de la inversión extranjera y las exportaciones en el contexto de una economía nacional orientada hacia el exterior. Con la desincorporación y privatización de empresas públicas se incentivó y facilitó la inversión de este último en rubros estratégicos como la petroquímica, la construcción de infraestructura, el transporte, la banca comercial, las telecomunicaciones, entre otros sectores.

Dentro de la inversión privada, es la inversión extranjera directa una de las que mayor atención demanda al aparato de Estado. Diversos son los incentivos brindados para atraer sus flujos: desde el acondicionamiento de infraestructura básica hasta la exención de impuestos y la canalización de gasto público para la formación y capacitación de capital humano que responda a las exigencias laborales de las empresas que operan a partir de altos 
estándares de calidad demandados en las cadenas de los sistemas internacionales de producción integrada.

d) La creación de condiciones y entramados institucionales para garantizar las transacciones económicas y los derechos de propiedad. Durante las últimas tres décadas, las élites tecnocráticas nacionales y transnacionales, más allá del fundamentalismo de mercado propio del Consenso de Washington, reconocieron la relevancia de las instituciones en el desempeño económico. Entre las medidas adoptadas por el aparato de Estado para ampliar el papel de las instituciones en la economía destacan la protección de los derechos de propiedad, el proceso de redefinición y adecuación de la regulación económica, la legislación económica -en especial la orientada al proceso productivo y a las relaciones laborales - y la referida firma de acuerdos comerciales (Poder Ejecutivo Federal, 1989, 1995, 2001, 2007 y 2013).

Como se especifica en los Planes Nacionales de Desarrollo elaborados desde 1989, tanto los procesos de privatización de empresas públicas como la reforma al Artículo 27 de la Constitución Política necesitaron de la definición y establecimiento de derechos de propiedad. Al privatizarse amplias franjas del sector público, resultó necesario definir y especificar los derechos de propiedad para generar certidumbre en los nuevos propietarios privados y garantizarles que -en el largo plazo- no les serían expropiados o renacionalizados los medios de producción y los activos. Por su parte, con las modificaciones al artículo 27 se procedía a disolver la propiedad ejidal de la tierra cultivable y transitar a una individualización de la misma mediante la escrituración que garantice la exclusividad de los derechos de propiedad; abriendo con ello la posibilidad de transferir voluntariamente a otros agentes dichos derechos.

Un mecanismo institucional adicional para procurar, desde el aparato de Estado, la viabilidad de la nueva estructuración de los mercados es la redefinición y adecuación de la regulación económica. Este proceso se emprende con el objetivo de generar adecuadas condiciones institucionales para las transacciones de los agentes económicos.

Gran parte de los precios de garantía que prevalecieron hasta la década de los noventa desaparecieron y el sector público dejó de jugar un papel importante en la comercialización de bienes y servicios -el cierre de FERTIMEX y de la CONASUPO es un ejemplo de ello. Además, las intervenciones directas del aparato de Estado en el proceso de desarrollo que se ejercieron con determinación hasta la década de los ochenta se tornaron selectivas, débiles $\mathrm{y}$, en muchos casos, nulas injerencias. Y si bien no podemos hablar de una desregulación absoluta, lo que presenciamos es una redefinición de los procesos de regulación de la economía que apunta a desechar el proteccionismo y la intervención estatal de antaño. 
La legislación económica introducida y modificada en los últimos lustros, en tanto instrumento institucional, se relaciona con las transformaciones experimentadas en el proceso económico. La flexibilización de los mercados laborales tras los cambios en la organización productiva; las reformas al sistema de seguridad social y los fondos de pensiones que individualizaron las cuentas de ahorro de los trabajadores y pasaron a formar parte de los flujos especuladores en los mercados de valores; la perpetuación de un sistema tributario que privilegia el gravamen al consumo por encima del gravamen al capital concentrado; y la socialización de las pérdidas derivadas de las quiebras en las carreteras concesionadas y del sistema bancario, mediante instrumentos como el Fondo Bancario para la Protección del Ahorro (FOBAPROA) (1995) -posteriormente nombrado Instituto para la Protección del Ahorro Bancario (IPAB) (1998)-, son todos ellos mecanismos legislativos que apuntan a generar arreglos institucionales para la valorización y acumulación del capital y para el fortalecimiento del empresariado privado transnacional beneficiado con la reprivatización de la banca comercial.

El mismo ingreso de México al GATT en 1986 y la profundización de las estrategias de apertura económica, condujo a la masiva firma de acuerdos y tratados comerciales con distintos Estados. Y aunque la economía nacional está anclada a la estadounidense -entre el 80 y el $90 \%$ del intercambio comercial desde 1994 se realiza con el vecino del norte- sin que exista la posibilidad de la diversificación en el corto y mediano plazos, se establecen las bases para la gestación de un entramado institucional capaz de posibilitar nuevas regulaciones del proceso económico. Es de destacar que el TLCAN se reduce a un área de libre comercio en condiciones asimétricas y sin la incorporación de fondos estructurales de compensación y de temas relacionados con la protección ambiental, la homologación salarial y la libre movilidad de la mano de obra.

e) La apertura y democratización del sistema político mexicano. Como parte de los mecanismos para la legitimación del Estado y la garantía de la gobernabilidad y ante la crisis de representatividad precipitada con los comicios electorales de 1988, se emprendieron en los dos siguientes sexenios, desde las mismas elites gubernamentales, reformas al sistema político mexicano que pretendieron su apertura y democratización mediante supuestos como el respeto al voto; el fortalecimiento del sistema de partidos; y la realización de elecciones confiables, transparentes, vigiladas y apegadas a la ley.

Sea como recomendación internacional suscrita en acuerdos comerciales, como parte de la armonización, homogeneización, estandarización y coordinación de las políticas públicas o como respuesta a la demanda interna de movimientos sociales que presionaron por la democratización del país ante las amplias posibilidades de fraude electoral, el sistema político mexicano se 
redefinió en lo que fueron sus pilares básicos: el presidencialismo autoritario y el partido cuasi oficial. Ambas instituciones fueron erosionadas sistemáticamente desde las élites tecnocráticas, sea mediante el abandono del discurso del nacionalismo revolucionario, el Programa Nacional de Solidaridad -que funcionó en los hechos como el cuasi partido político del Presidente de la República entre 1988 y 1994-, el impulso de reformas electorales que otorgaron un mayor poder y participación a los partidos políticos de oposición en la toma de decisiones, $\mathrm{y} / \mathrm{o}$ con el estímulo encubierto de la alternancia partidista suscitada en julio del año 2000.

Pese a procesos electorales sumamente cuestionados como el del año 2006, esta apertura y democratización del sistema político se convierte en una prioridad y una función relevante del Estado mexicano. Ello se evidencia con la canalización de vastas sumas del gasto público y con la formación, fortalecimiento y legitimación de entidades como el Instituto Federal Electoral (actualmente Instituto Nacional Electoral).

f) El diseño e instrumentación de políticas sociales para la compensación de la desigualdad y el empoderamiento de los grupos sociales marginados. Entre 1934 y 1982 se edificó en México un modelo de Estado interventor corporativo que contribuyó a la provisión de bienes y servicios básicos como la educación pública, la salud y la seguridad social; así como al otorgamiento de subsidios a la alimentación, al consumo, al transporte público y a la vivienda de interés social destinados a la población en general que accedía mediante prácticas clientelares y en apego a los lineamientos de las grandes centrales y organizaciones corporativas. Dichas prácticas, al privilegiar la atención de categorías profesionales y organizadas corporativamente - docentes, burócratas, militares, obreros pertenecientes a sindicatos afiliados a la Confederación de Trabajadores de México, etc.-, impidieron, salvo en materia educativa, la consolidación de políticas sociales dotadas de cobertura universal. Con este modelo de política social, el Estado absorbió los costos de la reproducción de la fuerza de trabajo, mientras que el empresariado privado fue eximido de ello y los salarios alcanzaron niveles predecibles.

En cambio, las políticas sociales ejercidas desde 1988 se sustentan en varios rasgos a saber: la racionalización del gasto público y del aparato burocrático que las instrumenta; la adopción de un perfil transitorio a medida que el mecanismo de mercado promueva, por sí mismo, una eficiente y equitativa asignación y distribución de los recursos que favorecerá a las amplias mayorías y reducirá a la población necesitada de asistencia social; la desconcentración, en cuanto a la ejecución y operatividad de los programas y el traslado de competencias y funciones del gobierno federal a los gobiernos de las entidades federativas o de los municipios -en algunos casos se experimentan 
traslados paulatinos hacia el sector privado y las organizaciones no gubernamentales-; y en la focalización selectiva o la atención y asistencia respecto a los grupos sociales más vulnerables y marginados que padecen la pobreza extrema, desmantelando con ello la política de subsidios generalizados en aras de procurar la disciplina fiscal. Cabe interpretar que estas estrategias suponen una nueva forma histórica de redistribución de la riqueza emprendida desde el aparato de Estado.

Se trata de políticas sociales que se subordinan a la política económica y a la mencionada reorientación de la vocación geopolítica y geoeconómica del aparato de Estado. Más en concreto aún, las políticas sociales como el Programa Nacional de Solidaridad, el PROGRESA, Oportunidades y Prospera presumen una vocación de compensación focalizada y selectiva respecto a los límites y promesas incumplidas de la democratización representativa y a los efectos y desequilibrios sociales negativos derivados de la aplicación de las políticas de ajuste y cambio estructural. Esto es, más que transitar de una democratización representativa a una de corte participativo, y más que combatir a fondo las desigualdades sociales, se trata de proporcionar paliativos que las compensen; de evitar un mayor deterioro de los grupos sociales en condiciones de pobreza y de construir una nueva forma de control político sobre dichos grupos mediante el denominado empoderamiento, el aprovechamiento de su capital social y la promoción de proyectos autogestivos en las comunidades.

Además, las políticas sociales participan en el proceso de acumulación del capital mediante la procuración de la estabilidad sociopolítica y el control del conflicto social -ambos necesarios para la atracción y establecimiento de la inversión extranjera-; las legislaciones que propician la privatización de los fondos de pensiones y favorecen a los mercados financieros, así como a través de la promoción del autoempleo a partir del estímulo de actividades microempresariales y la facilitación de financiamiento para que las micro, pequeñas y medianas empresas mejoren su productividad y rentabilidad.

\section{LAS COORDENADAS DEL ESTADO MEXICANO EN LA CARTOGRAFÍA ESTRATIFICADA DE LA ECONOMÍA MUNDIAL}

Al ser un Estado subdesarrollado y fragmentado, el mexicano es, a su vez, un Estado periférico que le da forma a una sociedad y una economía nacional insertadas de manera desventajosa y subordinada en el concierto de la expansión e integración global del capitalismo. En ello radican, en parte, los rasgos específicos que le diferencian de las instituciones estatales propias de otras formaciones sociales que se posicionan de manera ventajosa y hegemónica en la estructura económica mundial. 
De cara a una economía mundial cada vez más estratificada y signada por una división global del trabajo fundamentada en el acelerado cambio tecnológico y en la dimensión estratégica del conocimiento aplicado al mismo conocimiento y a la producción, el Estado mexicano -desarticulado y frágil en su estructura institucional, y asediado por la crisis fiscal- se limita a un papel marginal en el curso de la dialéctica desarrollo/subdesarrollo y se ciñe a los imperativos de crear un mínimo entorno institucional para los procesos de acumulación de capital. Ello, en sí, le distingue también del sector público de otras latitudes y de sus funciones e intervenciones esenciales. Abrevando de un ejercicio de comparabilidad internacional, es posible identificar los siguientes rasgos:

En los Estados Unidos, medios de innovación como el Silicon Valley, financiado en un principio por el Departamento de Defensa, se convirtió en un centro para la convergencia de nuevo conocimiento tecnológico de expertos, ingenieros y científicos, de una estructura industrial dinámica y de la creación de nuevas empresas (Castells y Hall, 2001; Castells, 2002). El programa espacial estadounidense de la década de los sesenta y el programa de la «Guerra de las Galaxias» iniciado en 1983 constituyeron destacadas acciones estatales en el fomento del avance tecnológico, particularmente de la industria electrónica. El mismo establecimiento y protección de monopolios como el de la empresa AT\&T y el financiamiento gubernamental de sus proyectos de investigación contribuyó al fortalecimiento de las bases para el desarrollo tecnológico. Buena cantidad de empresas dedicadas a la innovación tecnológica no hubiesen sobrevivido ni perdurado sin el financiamiento y la protección de los mercados proporcionados por el sector público estadounidense; en especial mediante los contratos militares (véase Castells, 2002:capítulo 1). En suma, la formación de redes de investigación y desarrollo es una prioridad en las estrategias adoptadas por la intervención estatal en ese país. No menos importante es el carácter geoestratégico y las consideraciones de seguridad nacional que alcanzan industrias como la aeroespacial, ampliamente intervenidas por el sector público e importantes por la tracción que ejercen sobre otras ramas y sectores productivos (Enríquez Pérez, 2014).

Estas acciones estatales se extienden a la intervención en las transacciones económicas para procurar la seguridad nacional, así como a la protección de industrias estratégicas como la microelectrónica para evitar que otras naciones ejerzan una competencia desleal que implique el control de insumos militares (Castells, 2002).

Otro rubro importante de la intervención pública en los Estados Unidos lo constituyeron, a lo largo del siglo Xx, las políticas sociales. En general, la seguridad social estadounidense comprende mecanismos de mercado con determinadas regulaciones gubernamentales, complementados con políticas sociales focalizadas que procuran suministrar bienes y servicios sociales a 
los individuos y familias que demuestran una condición de indigencia y marginación. Algunos estudiosos de estas políticas públicas argumentan que las intervenciones gubernamentales tienden a ser selectivas en el abatimiento de la pobreza y en la producción de bienes y servicios que la iniciativa privada no puede o no desea producir y suministrar, o bien, aquellos que son de rigurosa apropiación colectiva (Laurell, 1996).

Por su parte, dentro de la Unión Europea, en mayor o menor medida, predominan políticas públicas que propician la intensa y activa intervención del Estado en las economías de mercado y en el mantenimiento de los Estados de bienestar. Por ejemplo, en Inglaterra y Francia, la industria electrónica, apoyada de manera relevante por el sector público, estuvo ligada hasta los años ochenta a las telecomunicaciones y a la defensa. En tanto bloque regional con facultades en materia de integración económica y política, la Unión Europea fortalece la competencia internacional de la región mediante políticas públicas para el avance tecnológico que apuntalan la expansión de las principales empresas que disponen del gasto público para pactar alianzas con las corporaciones transnacionales provenientes de Japón y Estados Unidos y que les facilitan el suministro de conocimiento y tecnología. Además, las empresas transnacionales de los principales países europeos gozan de incentivos sistemáticos por parte de los gobiernos nacionales y de la misma Unión Europea en materia de desarrollo tecnológico y de protección de los mercados. Sectores importantes como la industria aeroespacial, la aviación comercial, la electrónica, el automotriz y la agricultura, prosperan a raíz del papel desempeñado por gobiernos como el inglés, el alemán y el francés en la estructuración de sus mercados y en el suministro de cuantiosos subsidios.

Más todavía, el importante desarrollo económico que experimentaron desde la década de los setenta los países del Este asiático, se atribuye a un modelo económico que privilegia la simbiosis entre el mercado y las instituciones del sector público; lo cual es parte de una concepción nacionalista del Estado desarrollista tal como ocurrió en Corea del Sur, Singapur y Japón. Dicha amalgama se evidencia en áreas como la redistribución del ingreso, el estímulo al avance tecnológico y la política industrial -generalmente proteccionista. Además de políticas públicas para procurar la estabilidad macroeconómica, la inversión en educación y capital humano, la seguridad de los sistemas financieros, las distorsiones limitadas de los precios, el desarrollo agrícola y la apertura hacia la tecnología extranjera, en el Este asiático se adoptan estrategias para ejercer una sistemática y racionalizada intervención estatal en el proceso económico, el impulso a industrias estratégicas, la generación y adquisición de nueva tecnología, y la integración respecto al mercado mundial (véase Aoki, Kim y Okuno-Fujiwara, 2000).

Algunos especialistas destacan una relación sinérgica entre el sector público y un régimen de mercado fundamentalmente privado, donde las 
acciones o la producción de alguno representa el insumo y los incentivos del otro (véase Wade, 1990). Una simbiosis donde el aparato de Estado estipulaba reglas e influía en la toma de decisiones del empresariado privado a partir de las concepciones del funcionariado sobre el adecuado modelo industrial y comercial a seguir.

El desarrollo del sudeste asiático no solo necesitó de la estabilidad macroeconómica. Fueron importantes también aquellas políticas públicas que, a través de una amalgama de estrategias orientadoras del mercado y otras dirigidas por las agencias estatales, fomentan y facilitan la acumulación de capital, la asignación eficiente de recursos y el acelerado desarrollo tecnológico (Aoki, Kim y Okuno-Fujiwara, 2000). Si bien la directa intervención estatal fue relevante en el Este asiático, estos mismos autores reconocen que lo fueron aún más los incentivos brindados a instituciones como las organizaciones empresariales, las asociaciones industriales, los intermediarios financieros, las organizaciones de trabajadores y agricultores, la cultura y costumbres empresariales, entre otras; además de la interacción que el gobierno sostiene con ellas. Los subsidios -otorgados por concurso y por la vocación exportadora- se canalizaron a las empresas más eficientes y aptas para promover esas mismas cualidades y para fortalecerlas en su expansión hacia los mercados internacionales. Si bien existió autoritarismo y paternalismo, las élites políticas adoptaron la perspectiva del «crecimiento compartido» para hacerse de legitimidad y para acercar los servicios educativos a las mayorías. Esta política educativa fue relevante para la formación y multiplicación del capital humano que permitió, a su vez, contar con una burocracia de calidad y distante de los vaivenes políticos, con contingentes de trabajadores altamente cualificados y con importantes capacidades empresariales.

Con un sector público pequeño, el activismo estatal en los países del Este asiático no consistió en sustituir, sino en facilitar la coordinación dentro del sector privado, asumiendo que ambos sectores no rivalizan por el control del proceso económico (Aoki, Murdock y Okuno-Fujiwara, 2000), o bien, en dirigir o gobernar el mercado para detonar procesos de desarrollo (Wade, 1990). Esto es, el desarrollo económico de esta región necesitó de la capacidad de la iniciativa privada para coordinar la actividad económica -sea mediante los mercados, dentro de las empresas, utilizando intermediarios, o en unión con el gobierno-, así como de las intervenciones estatales para fortalecer la coordinación y la cooperación en el sector privado mediante instrumentos de política pública como las rentas contingentes, el financiamiento a la innovación tecnológica, la restricción financiera, los consejos de deliberación y las estrategias para el escalonamiento de capitales y productos extranjeros.

Las tendencias del Estado latinoamericano difieren marcadamente de los precedentes ejemplos; aún en el contexto del viraje dado -durante los 
primeros quince años del nuevo milenio- por algunos gobiernos progresistas y nacionalistas en el cono sur tras el renovado impulso al perfil de Estados neodesarrollistas. En principio, durante los años ochenta y noventa, gran parte de los gobiernos latinoamericanos se orientaron, en mayor o en menor grado, a gestar las condiciones que facilitan el cambio estructural de sus economías para emprender una reinserción desventajosa en el mercado mundial.

Con la reestructuración de la economía mundial y el despliegue global de la manufactura flexible desde la década de los setenta, la nueva división internacional del trabajo y el rezago tecnológico experimentado en los países latinoamericanos posicionaron a la región como un territorio especializado en la producción de insumos -en especial de materias primas, commodities y de autopartes- para proveerse a las redes empresariales globales. Esta reinserción, que como afirmamos suele ser desventajosa y subordinada, tiene en los aparatos de Estado a uno de sus principales promotores y gestores. Con la crisis de la deuda, la autonomía en la toma de decisiones gubernamentales es trastocada e influida por diversas circunstancias, agentes y actores tanto nacionales como internacionales. A raíz de esto, la principal apuesta de los gobiernos de la región consiste en incentivar y facilitar la competitividad de algunos sectores productivos ante la creciente integración global del capitalismo.

En este escenario, la llamada reforma del Estado -al menos durante la década de los noventa- tuvo como principales líneas de acción la apertura de las economías nacionales y el ajuste de la balanza de pagos, la retracción del sector público a través de las privatizaciones, la estabilización macroeconómica a partir de la redefinición de los incentivos y los precios relativos, y la transformación y limitación de sus intervenciones en el proceso económico. No menos importantes fueron las reformas institucionales orientadas a consolidar y brindar viabilidad al Consenso de Washington. Sin embargo, pese al viraje neodesarrollista dado por los gobiernos progresistas sudamericanos entre el 2003 y el 2015, la región y sus élites políticas se debaten en torno a la falsa dicotomía de más Estado o más mercado; imponiéndose durante largos periodos la racionalidad de este último y asumiéndose la creencia en la espontaneidad del «libre comercio». De tal manera que -en aras de adoptar «buenas» políticas y «buenas» instituciones-ceden a la tentación de retirar la escalera del proteccionismo que permitió a las potencias económicas actuales trascender en su historia económica y afianzar sus sectores agrícolas, industriales y tecnológicos (sobre este argumento véase Chang, 2004).

Lo que subyace en el fondo de esta falsa disyuntiva es la disputa por el control del proceso económico, así como por la orientación y perfil del Estado en torno a tópicos nodales como la apropiación de la plusvalía y la distribución de la riqueza. Más aún, la intervención del Estado y el tipo de funciones que despliega no es una mera cuestión técnica y de procuración de 
eficiencia; es, ante todo, la posibilidad de condensar los valores y principios de una comunidad respecto a la estructuración de la vida social y a la atención de sus problemas públicos medulares. Y justo esos valores y principios que le dan forma al tipo de instituciones que se otorga una sociedad, definirán el tipo de Estado que construye, así como las coordenadas que ocupa en la cartografía de la estratificada economía mundial.

\section{CONSIDERACIONES FINALES SOBRE LA INVESTIGACIÓN}

Comprender las funciones del Estado en torno a la dialéctica desarrollo/ subdesarrollo y los cambios que históricamente experimentan, supone comprender las transformaciones experimentadas por el capitalismo y los impactos que ello tiene en las concepciones que subyacen en el diseño y ejercicio de las políticas públicas. Supone también comprender que la planeación del desarrollo y las decisiones públicas no solo dependen de condicionamientos, factores y actores estrictamente nacionales, sino que están expuestas a la teledirección que ejercen los organismos internacionales y a la lógica que asumen los espacios globales para la toma de decisiones y las comunidades epistémicas trans-territoriales que en ellos se configuran a partir del posicionamiento de poderes fácticos que no necesariamente están arraigados en los espacios locales/nacionales en cuestión; pero que pretenden hacer valer una agenda de política pública.

Lo anterior implica que en una sociedad subdesarrollada como México se tome en cuenta la abierta crisis de Estado que tiene como trasfondo el socavamiento y depredación de las instituciones ante la proliferación y expansión de fuerzas y poderes fácticos que -desde afuera y desde adentro, desde arriba y desde abajo- le disputan la hegemonía a esa macroestructura institucional. Esta crisis de Estado tiende a magnificarse con la intensificación de los procesos de globalización y con la erosión de la soberanía en asuntos estratégicos. Y si bien el Estado mexicano no desaparece en sus funciones elementales ni muta en un Estado fallido, sus intervenciones son desarticuladas, selectivas, pasivas, precarias y hasta ausentes en aras de no trastocar los imperativos del fundamentalismo de mercado.

Finalmente, cabe matizar que esta crisis institucional es correlato de la contradictoria manifestación social y territorial de la dialéctica desarrollo/ subdesarrollo y que si bien las específicas funciones contemporáneas del Estado son acotadas y tienden a achicar son intervenciones, resulta preciso continuar estudiando el carácter y el sentido de dichas funciones y las debilidades que muestran respecto a la construcción de mercados, la distribución de la riqueza y la procuración de la seguridad pública; no sin perder de vista la reconfiguración de las élites políticas nacionales y la relevancia que adquiere la convergencia, estandarización, sincronización armonización, 
homogeneización y coordinación de las políticas públicas a escala planetaria. De ahí que sea posible platear algunas preguntas incisivas que contribuyan a ampliar las líneas de investigación y a abrir caminos para las posibles respuestas: ¿Cómo revalorar y reincorporar los fecundos estudios sobre el Estado esbozados por la sociología política y la economía política mexicanas en los esfuerzos por comprender los rasgos característicos y específicos de esta macroestructura institucional en la actualidad? ¿De qué manera podría ampliarse el conocimiento sistemático en torno al sentido de las decisiones públicas y de las funciones e intervenciones del Estado mexicano en la dialéctica desarrollo/subdesarrollo? ¿Cómo construir comunidades interdisciplinarias que estudien las distintas aristas, fuerzas, factores, circunstancias y actores internos y externos que inciden en las decisiones públicas y en las funciones del Estado? ¿Cuáles son las especificidades que caracterizan al Estado mexicano respecto al sector público de otras latitudes, y cómo se toman allí las decisiones públicas? ¿Qué se necesita para que ese nuevo conocimiento influya en la vida pública y en la reorientación del Estado mexicano? Estos y otros interrogantes son cruciales para evidenciar la depredación de las instituciones estatales y de sus funciones esenciales de cara a la gravitación que ejercen los espacios globales para la toma de decisiones $\mathrm{y}$, particularmente, los organismos internacionales que difunden una concepción etnocéntrica sobre el desarrollo. Más apremiantes resultan las posibles respuestas y argumentos de cara a la crisis del pensamiento utópico que caracteriza a las élites políticas mexicanas que se resisten, pese a los cambios electorales, a emprender una verdadera y efectiva reforma del Estado que revierta la crisis institucional y fundamente la (re)construcción de proyectos alternativos de nación que atiendan las desigualdades sociales y el carácter disruptivo y contradictorio de la misma dialéctica desarrollo/subdesarrollo.

\section{FUENTES DE CONSULTA UTILIZADAS EN LA INVESTIGACIÓN}

AoKI, M.; Kim, H.-Ki y OKUNO-FuJIWARA, M. [2000 (1997)]. «Introducción», en: Masahiko Aoki, Hyung-Ki Kim y Masahiro Okuno-Fujiwara (Coordinadores), $E l$ papel del gobierno en el desarrollo económico del Asia Oriental. Análisis institucional comparado, México, Fondo de Cultura Económica (FCE), pp. 5-14.

—, Murdock, K. y Okuno-Fujiwara, M. [2000 (1997)]. «Más allá de The East Asian Miracle. Introducción al enfoque del fortalecimiento del mercado», en: Masahiko Aoki, Hyung-Ki Kim y Masahiro Kuno-Fujiwara (Coordinadores), El papel del gobierno en el desarrollo económico del Asia Oriental. Análisis institucional comparado, México, FCE, pp. 15-62.

BANCO Mundial (1997). Informe sobre el desarrollo mundial, 1997. El Estado en un mundo en transformación, Washington, D. C., Banco Mundial. 
(2001). Informe sobre el desarrollo mundial 2002. Instituciones para los mercados, Washington, Mundi-Prensa Libros para el Banco Internacional de Reconstrucción y Fomento/Banco Mundial.

- (2004). Informe sobre el desarrollo mundial 2005. Un mejor clima para la inversión en beneficio de todos, Bogotá, Banco Mundial, Mundi-Prensa Libros y Alfaomega Grupo Editor.

Calva, J. L. [1999 (1993)]. El modelo neoliberal mexicano. Costos, vulnerabilidad, alternativas, México, Juan Pablos Editor.

- (2000). México más allá del neoliberalismo. Opciones dentro del cambio global, México, Plaza \& Janes Editores.

- (2008). Los programas de ajuste económico en México y América Latina, México, Centro Nacional de Promoción Social, A. C.

CÁrdenas, E. (1996). La politica económica en México, 1950-1994, México, FCE, Fideicomiso Historia de las Américas y Colegio de México.

Castells, M. [2002 (1996)]. La era de la información. Economía, Sociedad y cultura (La sociedad red), volumen I, México, Siglo Veintiuno Editores.

- y HaLl, P. [2001 (1994)]. Las tecnópolis del mundo. La formación de los complejos industriales del siglo XXI, Madrid, Alianza Editorial.

Chang, H.-J. [2004 (2002)]. Retirar la escalera. La estrategia del desarrollo en perspectiva histórica, Madrid, Libros de la Catarata y Universidad Complutense de Madrid.

ENRÍQUEZ PÉREZ, I. (2002). «Los procesos de globalización y la política pública como instrumento reestructurador del espacio urbano en México», en: Globalización: Revista mensual de economía, sociedad y cultura, enero, http://rcci.net/globalizacion/2002/fg217.htm

- (2010). «La evolución del pensamiento sobre el desarrollo en el Fondo Monetario Internacional y el Banco Mundial: un análisis comparativo sobre su gravitación en América Latina», en: Trayectorias. Revista de Ciencias Sociales, Monterrey, Universidad Autónoma de Nuevo León, Volumen XII, n. ${ }^{\circ}$ 31, julio-diciembre, pp. 31-60.

- (2011). «Las concepciones sobre el desarrollo regional en las políticas públicas del sur-sureste mexicano y en los proyectos autogestivos de las comunidades locales: una contrastación a la luz de las inconsistencias del Plan Puebla-Panamá», en: OBETS. Revista de Ciencias Sociales, Alicante, Universidad de Alicante, volumen 6, n. $^{\circ} 2$, diciembre de 2011, pp. 185-218.

- (2014). «Las innovaciones organizacionales y tecnológicas en la industria aeroespacial: un análisis de su comportamiento a la luz de la comparabilidad internacional», en: Alfonso Bouzas Ortiz (Coord.), Globalización y trabajo. Cambios tecnológicos, migración y nueva regulación laboral, México, Instituto de Investigaciones Económicas/UNAM. En: http://ru.iiec.unam.mx/2400/

- (2017). «Los organismos internacionales y su incidencia en la dialéctica desarrollo/subdesarrollo: notas introductorias para comprender su naturaleza, funciones y comportamiento», en: Revista de Relaciones Internacionales de la UNAM, México, Centro de Estudios Internacionales de la Facultad de Ciencias Políticas y Sociales/UNAM, n. ${ }^{\circ}$ 127, enero-abril, pp. 49-81.

- y Flores SANDOVAL, R. D. (2002). «El proceso de Desarrollo y la crisis ecológica ante la globalización. El caso concreto de las omisiones medioambientales 
del Plan Puebla-Panamá», en: Globalización: Revista mensual de economía, sociedad y cultura, junio, http://rcci.net/globalizacion/2002/fg252.htm

González Casanova, P. [1975 (1965)] (1975). La democracia en México, México, Editorial Era.

Grupo Nuevo Curso de Desarrollo (2012). México frente a la crisis: hacia un nuevo curso de desarrollo. Manifiesto: lineamientos de política para el crecimiento sustentable y la protección social universal, México, UNAM.

GuIllén Romo, A. (2000). México hacia el siglo XXI: Crisis y modelo económico alternativo, México, Universidad Autónoma Metropolitana-Iztapalapa y Editorial Plaza y Valdés.

- (2012). «México, ejemplo de las políticas anti-desarrollo del Consenso de Wahsington», en: Revista Estudos Avançados, São Paulo, Instituto de Estudos Avançados de la Universidade de São Paulo, volumen 26, n. ${ }^{\circ} 75$, mayo-agosto, pp. 57-76.

Huerta GonzÁlez, A. (2004). La economía política del estancamiento, México, Editorial Diana.

- (2016). El estancamiento económico y la desigualdad del ingreso. Dos procesos que se retroalimentan, México, UNAM.

LAURELL, A. C. (1996). «Regímenes de política social y satisfacción de necesidades sociales», en: Rodolfo García Zamora (Coordinador modular), Funciones del Estado en el desarrollo económico y social, México, Universidad Autónoma de Ciudad Juárez, Universidad autónoma de Zacatecas y Juan Pablos Editor, pp. 91-112.

McConnell, C. R. [1972 (1970)]. Curso básico de economía, Madrid, Editorial Aguilar.

Poder Ejecutivo Federal [1983 (1985)]. «Plan Nacional de Desarrollo 19831988», en: Antología de la planeación en México (1917-1985). Sistema Nacional de Planeación Democrática (1982-1985), volumen X, México, Secretaría de Programación y Presupuesto y FCE, pp. 137-518.

- (1989). Plan Nacional de Desarrollo 1989-1994, México, Secretaría de Programación y Presupuesto.

— (1995). Plan Nacional de Desarrollo 1995-2000, México, Secretaría de Hacienda y Crédito Público.

— (2001). Plan Nacional de Desarrollo 2001-2006, México, Presidencia de la República.

(2007). Plan Nacional de Desarrollo 2007-2012, México, Gobierno de los Estados Unidos Mexicanos/Presidencia de la República.

- (2013). Plan Nacional de Desarrollo 2013-2018, México, Gobierno de la República.

POLANYI, K. [1992 (1944)]. La gran Transformación. Los orígenes políticos y económicos de nuestro tiempo, México, FCE.

Presidencia de la República (2001). Plan Puebla-Panamá (Documento Base. Capítulo México), México, Presidencia de la República, presentado el 12 de marzo.

SAXE-FERnÁndEZ, J. (1988). «Deuda externa y desnacionalización integral», en: Revista Mexicana de Ciencias Políticas y Sociales, México, UNAM, año XXXIV, n. ${ }^{\circ} 134$, octubre-diciembre, pp. 71-91. 
TORRes TORRes, F. y GASCA ZAMORA, J. (coordinadores). Los espacios de reserva en la expansión global del capital. El sur-sureste mexicano de cara al Plan Puebla-Panamá, México, Instituto de Investigaciones Económicas, Facultad de Economía e Instituto de Geografía de la UNAM y Plaza y Valdés Editores, pp. 297-319. 


\title{
LA TRANSFORMACIÓN DE LAS FUNCIONES DEL ESTADO MEXICANO EN TORNO A LA DIALÉCTICA DESARROLLO/SUBDESARROLLO: INCURSIONES A LA LUZ DE LA CRISIS INSTITUCIONAL CONTEMPORÁNEA
}

\author{
The transformation of the functions of the Mexican State \\ around the dialectic development / underdevelopment: \\ incursions in light of the contemporary institutional crisis
}

\author{
Isaac Enríquez Pérez \\ Universidad Nacional Autónoma de México \\ isaacep@unam.mx
}

http://dx.doi.org/10.18543/ed-67(1)-2019pp185-221

\section{Copyright}

Estudios de Deusto es una revista de acceso abierto, lo que significa que es de libre acceso en su in tegridad. Se permite su lectura, la búsqueda, descarga, distribución y reutilización legal en cualquier tipo de soporte sólo para fines no comerciales, sin la previa autorización del editor o el autor, siempre que la obra original sea debidamente citada y cualquier cambio en el original esté claramente indicado

Estudios de Deusto is an Open Access journal which means that it is free for full access, reading, search, download, distribution, and lawful reuse in any medium only for non-commercial purposes, without prior permission from the Publisher or the author; provided the original work is properly cited and any changes to the original are clearly indicated. 